\title{
Sinus of valsalva aneurysm - case report
}

\section{(DDDario Dilber *}

Čakovec County Hospital, Čakovec, Croatia

\section{RECEIVED:}

December 8, 2020

ACCEPTED:

December 18, 2020

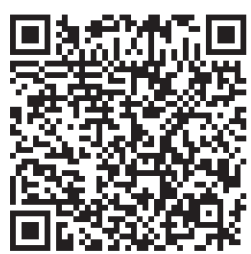

$\square$ Cardiologia Croatica 2021:16(1-2):34.
KEYWORDS: sinus of Valsalva, dilatation, aneurysm

CITATION: Cardiol Croat. 2021;16(1-2):34-5. | https://doi.org/10.15836/ccar2021.34

*ADDRESS FOR CORRESPONDENCE: Dario Dilber, Županijska bolnica Čakovec, I.G.Kovačića 1e, HR-42000 Čakovec, Croatia. / Phone: +385-91-4683101 / E-mail: dario.dilber@gmail.com

ORCID: Dario Dilber, https://orcid.org/0000-0002-0062-4708

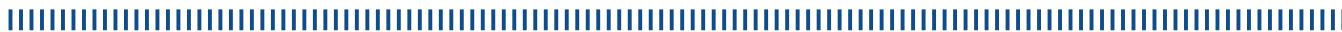

Introduction: Sinus of Valsalva aneurysm (SOVA) is an abnormal dilatation of the aortic root located between the aortic valve annulus and the sinotubular junction. The function of the sinuses is to prevent occlusion of the coronary artery ostia during systole when the aortic valve opens. The estimated rate of Sinus of Valsalva aneurysm is approximately $0.09 \%$ of the general population ${ }^{1}$. Sinus of Valsalva aneurysm can be either congenital, associated to connective tissue disorders, BAV, hypoplastic left heart syndrome or acquired, associated to atherosclerosis, chest injury or infective diseases. Sinus of Valsalva aneurysms usually affect the right coronary sinus (65-85\%), followed by the noncoronary sinus (10-30\%), and the left $(<5 \%)$ coronary sinus ${ }^{2}$. Males are four times more likely to be affected than females ${ }^{1}$. Patients that have sinus of Valsalva aneurysm may be asymptomatic or may present with dyspnea, chest pain, palpitations or syncope. Non-ruptured Sinus of Valsalva aneurysm thrombosis can lead to coronary ostia occlusion. Rupture of the right and noncoronary sinuses typically results in communication between the aorta and either the right atrium or the right ventricular outflow tract, thus creating a left to right shunt and requires surgical management. Non-ruptured sinus of Valsalva aneurysm should be surgically or percutaneously repaired with aneurysms greater than $5.5 \mathrm{~cm}$ without comorbidities and should be considered when there is a growth rate of more than $0.5 \mathrm{~cm} /$ year with beta-blocker in therapy. ${ }^{1-3}$

Case report: A 52-year- old male with past medical history of a fall from height in 2004 presented to a cardiologist with complaints of shortness of breath and chest pain. He was sent for exercise stress test which demonstrated a reduced functional capacity with ECG changes in inferior leads at rest (Figure 1) He was referred for a transthoracic echocardiogram, which showed aortic root dilation to $5.8 \mathrm{~cm}$ and aneurysmal dilatation of the right sinus of Valsalva with moderate aortic regurgitation (Figure $\mathbf{2}$ Figure 3) and hypocontractility and fibrotic changes of inferoposterior wall of the left ventricle. Coronarography showed no significant disease (Figure 4). Finally, cardiac computed tomography angiography was performed (Figure 5), which confirmed dilation at the right coronary cusp, and patient was referred to a heart surgeon.

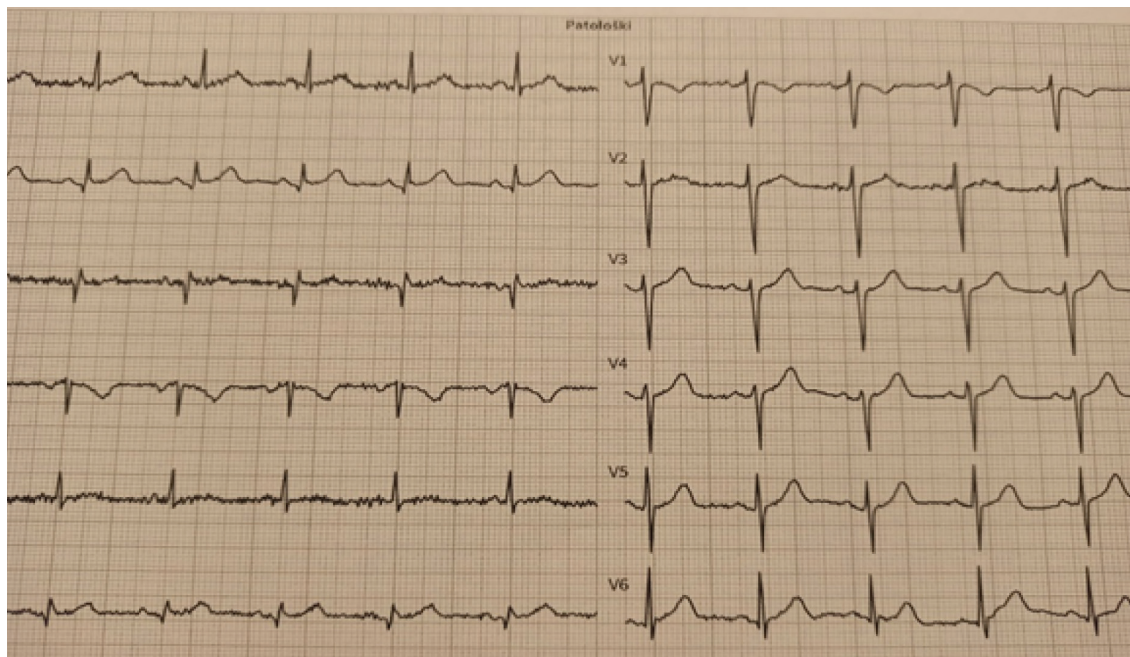

FIGURE 1. Electrocardiogram showing changes in inferior leads. 

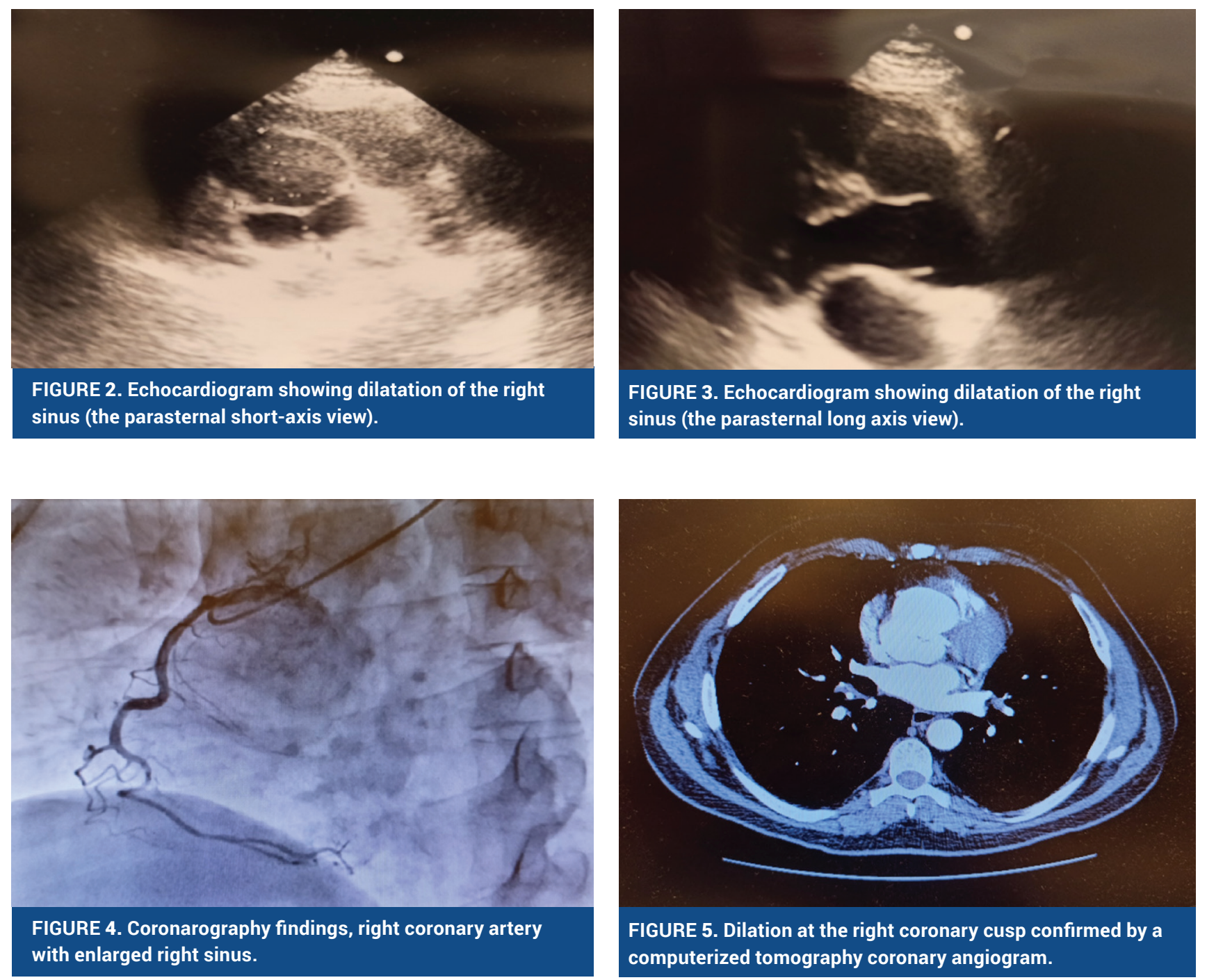

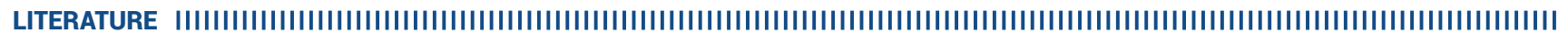

1. Weinreich M, Yu PJ, Trost B. Sinus of valsalva aneurysms: review of the literature and an update on management. Clin Cardiol. 2015 Mar;38(3):185-9. https://doi.org/10.1002/clc.22359

2. Feldman DN, Roman MJ. Aneurysms of the sinuses of Valsalva. Cardiology. 2006;106(2):73-81. https://doi.org/10.1159/000092635

3. Hiratzka LF, Bakris GL, Beckman JA, Bersin RM, Carr VF, Casey DE Jr, et al; American College of Cardiology Foundation/American Heart Association Task Force on Practice Guidelines; American Association for Thoracic Surgery; American College of Radiology; American Stroke Association; Society of Cardiovascular Anesthesiologists; Society for Cardiovascular Angiography and Interventions; Society of Interventional Radiology; Society of Thoracic Surgeons; Society for Vascular Medicine. 2010 ACCF/AHA/AATS/ACR/ASA/SCA/SCAI/SIR/STS/ SVM guidelines for the diagnosis and management of patients with Thoracic Aortic Disease: a report of the American College of Cardiology Foundation/American Heart Association Task Force on Practice Guidelines, American Association for Thoracic Surgery, American College of Radiology, American Stroke Association, Society of Cardiovascular Anesthesiologists, Society for Cardiovascular Angiography and Interventions, Society of Interventional Radiology, Society of Thoracic Surgeons, and Society for Vascular Medicine. Circulation. 2010 Apr 6;121(13):e266-369. https://doi.org/10.1161/CIR.0b013e3181d4739e 